\title{
Health Beliefs Regarding Uptake of Hypertension Screening in an Urban Setting: A Population Segmentation Strategy
}

\author{
Bharathi Valantina Neelakandan', Srimathi Gopalakrishnan', Harshini Ramachandran' , Anuradha R², \\ Vijayaprasad Gopichandran²
}

\begin{abstract}
Introduction: The prevalence of hypertension is rapidly rising in low and middle income countries. Detection of hypertension largely depends on screening of healthy individuals. Therefore, screening behaviour is very important in early diagnosis and treatment. Objectives: This study aimed at surveying the health beliefs with respect to hypertension screening, of a typical urban community in Chennai, south India and segmenting the population into clusters based on their health beliefs in order to effectively target behaviour change interventions. Methods: A cross sectional survey was conducted among 140 adult men and women selected by a multistage random sampling method in Chennai. A questionnaire to collect information on hypertension screening behaviours, health belief model domains such as perceived susceptibility, severity, benefits, barriers and cues to action was administered. Results: Factor analysis of the questions revealed the same five health belief domains with good factor loadings on each question. Based on their responses the participants were clustered into 6 groups by $\mathrm{k}$ means cluster analysis namely, (1) extrinsically motivated with perception of severity and (2) without, (3) intrinsically motivated with risk acceptance and (4) risk denial, (5) unfavourable health belief with negative attitudes focussing mainly on barriers and (6) overall apathy towards screening. Older age, male gender, married status and nuclear type of family were important factors positively influencing health beliefs regarding hypertension screening. Conclusions: The health belief model can be effectively used to segment the population into groups that are different by virtue of their motivation types and attitudes towards screening for hypertension. Key words: Health belief, Hypertension Screening, Screening behaviour.
\end{abstract}

\section{Bharathi Valantina Neelakandan', Srimathi Gopalakrishnan', Harshini Ramachandran', Anuradha $\mathbf{R}^{2}$, Vijayaprasad Gopichandran²}

'ESIC Medical College and PGIMSR, Chennai 600078, INDIA.

2Department of Community Medicine, ESIC Medical College and PGIMSR, Chennai 600078, INDIA.

\section{Correspondence}

Dr. Vijayaprasad Gopichandran

Assistant Professor, Department of

Community Medicine, ESIC Medical

College and PGIMSR, KK Nagar,

Chennai 600078, Tamil Nadu, INDIA

Mobile no: +919445226806

Email: vijay.gopichandran@gmail.com

History

- Revised Date: 10-11-2017

DOI : 10.5530/ijmedph.2018.1.3

Article Available online

http://www.ijmedph.org/v8/i1

\section{Copyright}

(C) 2018 Phcog.Net. This is an openaccess article distributed under the terms of the Creative Commons Attribution 4.0 International license.
- Submission Date: 21-06-2017

- Accepted Date: 21-11-2017

\section{INTRODUCTION}

The prevalence of hypertension has shown a steady increase in low and middle income countries (LMIC). ${ }^{1}$ The prevalence has risen from a $5 \%$ three decades ago to about $20-30 \%$ in urban areas and $12-15 \%$ in rural areas in recent times in India. ${ }^{2,3}$ Drastic change in life styles over the past five decades due to changes in patterns of work and livelihood are probably a major contributor to the increase in prevalence of hypertension. ${ }^{2}$ This rising prevalence of hypertension has serious consequences as more than $16 \%$ of the ischemic heart disease burden, $21 \%$ of peripheral vascular diseases, and $29 \%$ of strokes are attributable to hypertension. ${ }^{4}$ Hypertension like many non-communicable diseases is silent in nature and hence can be detected early only by screening. Early detection and appropriate management can lead to good control of the blood pressure and thus reduction in morbidity and mortality. ${ }^{5}$ In LMICs there is insufficient evidence to support a population level screening method as a public health intervention. ${ }^{6}$ However, opportunistic screening during primary care clinic visits has been advocated as a strategy for screening adults for hypertension. ${ }^{7,8}$
In developing health care settings, most people do not have routine health care check-up or primary care visits. Hospital visits are usually associated with some form of illness. The public hospitals are generally overcrowded and the provider's time spent per patient is very less. In this situation, most primary care is provided by private health system and this leads to high health care costs, which the poor cannot afford. These are some practical difficulties of opportunistic screening of people for hypertension during primary care visits. ${ }^{9}$ It is not uncommon to detect hypertension among patients for the first time when they present to the hospital with advanced complications.

Therefore, most of hypertension screening in these settings depends on the individual's awareness about the disease, perceptions about the disease, motivation to get themselves screened, and visiting a facility to get their blood pressure checked.

In a study from India, it was found that the community perceived hypertension to be a disease with symptoms and only people with symptoms should get tested for hypertension..$^{10}$ Many people were unaware of their hypertension status and there was a perceived need for awareness and screening programs. Another
Cite this article : Neelakandan BV, Gopalakrishnan S, Ramachandran H, Anuradha R, Gopichandran V. Health Beliefs Regarding Uptake of Hypertension Screening in an Urban Setting: A Population Segmentation Strategy. Int J Med Public Health. 2018;8(1):11-17. 
systematic review of lay person's perceptions about hypertension also revealed that people from both developed countries and LMICs said that hypertension is a disease with symptoms and treatment of hypertension will lead to symptom relief. ${ }^{11}$ Therefore there is a need to understand the factors that would motivate a person to take up screening for hypertension even before symptoms appear.

The health belief model is a behaviour change theory proposed in 1952, and has stood the test of time for over 60 years now, and captures the factors which make a person espouse a change in health behaviour. ${ }^{12,13}$ The model proposes that a change in health behaviour is influenced by perceived susceptibility, perceived severity, perceived benefits, perceived barriers and cues to action. Segmenting populations based on health beliefs has been found to be useful for targeting effective health promotion messages. This has been performed for health beliefs related to cancer and genetic diseases. ${ }^{14,15}$

This study aimed at surveying the health beliefs with respect to hypertension screening, of a typical urban community in Chennai, south India and segmenting the population into groups based on their health beliefs in order to effectively target behaviour change interventions.

\section{MATERIALS AND METHODS}

A cross sectional survey was conducted in a typical urban setting in Chennai, a city in southern part of India. The coastal city has a total population of 4.6 million with a literacy rate of $90 \%$ and sex ratio of 989 per 1000 males. ${ }^{16}$ A study from Chennai showed a prevalence of hypertension of about $20 \%$ with only $33 \%$ being aware of their hypertension status. ${ }^{17}$ Adult men and women aged 30 years and above, who were not previously diagnosed and treated for hypertension were included in the survey. A multistage sampling procedure was applied. One ward in Chennai was selected randomly, all the streets in the ward were listed. Ten streets were selected randomly from the list. The number of households were listed in each of the selected streets and households sampled by systematic random method. Number of households sampled in each street was proportional to the overall number of households in the street. All eligible adults were enumerated within each household and one person sampled randomly for the survey. Figure 1 explains the flow of the sampling used in this study. Based on a previous study the level of good knowledge of hypertension was $46.6 \%{ }^{18}$ Since the awareness about hypertension is a very important pre-requisite for health beliefs and as there were no previous studies which have looked at prevalence of health beliefs in this community, this prevalence was used for calculation of sample size. Therefore for estimating this level of knowledge with a 95\% confidence level and $20 \%$ relative precision the sample size was estimated to be 115. Given a strong homogeneity of the households in the ward that was selected, a very conservative design effect of 1.2 was considered and overall sample size required was 140 . A questionnaire containing basic demographic information, family history of chronic NCDs, whether they had undergone hypertension screening in the last two months, questions on health belief model variables of perceived susceptibility, perceived severity, perceived benefits, perceived barriers and cues to action adapted from a previous study were used. ${ }^{19}$ The health belief model questionnaire that was adopted was given to experts in public health and tested for content and face validity. Socio-economic status was assessed using the Modified Kuppuswamy Scale..$^{20}$ The questionnaires translated in Tamil language were administered to the sampled respondents by five trained investigators. The questionnaire administration was standardized across all the five data collectors by rigorous training and rehearsals. Appropriate permissions were sought and obtained from the authorities before data collection. The data were collected in Epi Info version 7 software in mobile handheld devices. The data were exported to SPSS Statistical Package version 21 and analysed. Simple descriptive statistics were analysed and reported. In order to reduce the data into the dimension of the health belief questionnaire and obtain dimension wise factor scores, exploratory factor analysis with extraction of 5 components corresponding to the five health belief variables, using principle component analysis method and varimax rotation was performed. Hierarchical cluster analysis was performed using the factor scores and the agglomeration schedule used to identify the number of possible clusters. K means cluster analysis was performed and cluster centres identified to group the sampled population based on their health beliefs. The characteristics of people in these individual segments were compared using Chi square test and wherever the cells had values less than 5, Fisher exact test was used. The study was approved by the Institutional Ethical Committee of theESIC Medical College, Chennai after expedited review. Written informed consent was obtained from all participants before the study. Adequate privacy was ensured during the interviews and confidentiality of the data was maintained.

\section{RESULTS}

A total of 140 participants were interviewed for the study. The characteristics of the study participants are shown in Table 1.

It is seen that a majority (60\%) of the study participants were below 50 years of age. There was a preponderance of female participants and majority belonged to small nuclear families. About $70 \%$ of the respondents belonged to the upper middle and upper class socioeconomic category. After summing up the scores of the Likert type response to each question in the five health belief domains, the distribution of the total scores was plotted and is shown in Figure 2. It is noted that the perceived susceptibility, severity and barriers scores are nearly normally distributed. However, the perceived benefits scores are more skewed to the lower values and cues to action skewed to higher values. Figure 3 shows the correlation between scores on these five domains of the health beliefs regarding hypertension screening. It is seen that there are statistically significant positive correlations between perceived benefits-severity $(\mathrm{r}=0.215 ; p<0.05)$, susceptibility-severity $(\mathrm{r}=0.224 ; p<0.05)$, barriers-severity $(\mathrm{r}=0.206 ; p<0.05)$, benefits-susceptibility $(\mathrm{r}=0.312 ; p<0.05)$, benefits-cues to action $(\mathrm{r}=0.178 ; p<0.05)$, and significant negative correlation between perceived benefits-barriers $(r=-0.158 ; p<0.05)$. The correlation between these domains indicates that they all are strongly inter connected and influence each other. The exploratory factor analysis to extract five factors had a good model fit as indicated by the Bartlett's test of sphericity with a $p$ value $<0.05$. The factors were extracted based on the eigen value principle. The five factor solution explained $42.4 \%$ of the total variance. KeiserMeyer-Olkin test value was 0.667 indicating a fair sampling adequacy. The five components, the statements that featured into these components and their respective factor weights are shown in Table 2. It is seen that the items are appropriately loaded into their respective domains.

The factor scores in each of these five health belief domains were used for cluster analysis. The sample of respondents were divided into six clusters. The cluster centres of each domain's factor score are shown in Table 3.

It is observed that cluster 1 comprises of people who have high perception of severity of hypertension and are driven by external cues to action. Cluster 2 has people who are driven by their perceptions of severity of disease and benefits of screening and not much by external cues. Cluster 3 comprises of people who focus on the barriers and perceive no benefits of screening. Members of cluster 4 perceive the benefits of screening and severity but deny their susceptibility to hypertension. Members of cluster 5 are strongly driven by external cues to action and do not perceive severity of the disease. The last cluster has people whose attitudes in all domains is very low with overall unfavourable health belief.

Table 4 shows the characteristics of the members of each cluster. 


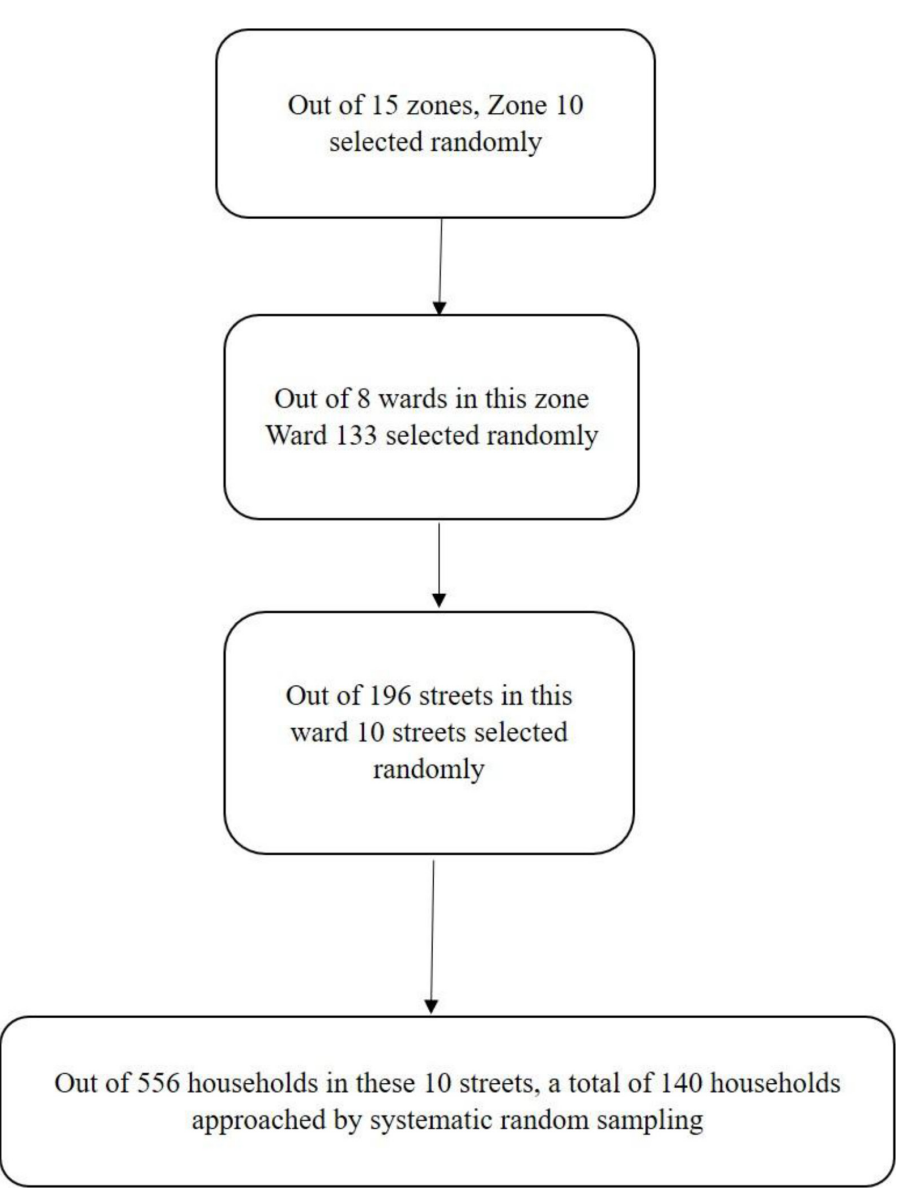

Figure 1: This Figure shows the flow diagram of the sampling strategy used in this study.

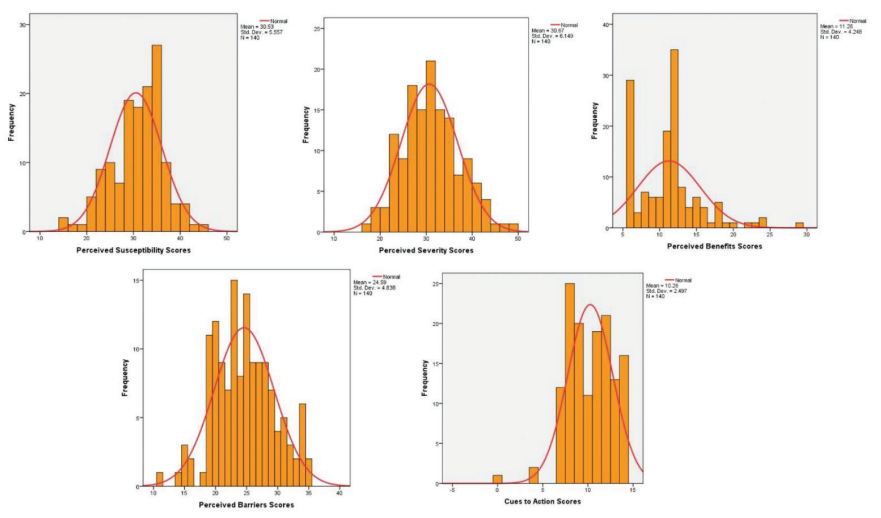

Figure 2: Distribution of scores in the various domains of health belief model. It is seen that scores of Cues to Action is positively skewed and scores of Perceived benefits negatively skewed. Other scores are nearly normally distributed.

It is seen that among women there are more people with unfavourable health beliefs and risk denial compared to men. Also there are more unfavourable health beliefs among unmarried people compared to their married counterparts. Among those living in joint families there are more people with unfavourable health beliefs with negative attitudes and risk denial. There were more people with unfavourable health beliefs in the younger age group of 30-40 years.

\begin{tabular}{|c|c|c|c|}
\hline S.No & Characteristic & Category & Number (\%) \\
\hline \multirow[t]{3}{*}{1} & Age & 30 to 39 years & $42(30)$ \\
\hline & & 40 to 49 years & $41(29.3)$ \\
\hline & & 50 to 59 years & $57(40.7)$ \\
\hline \multirow[t]{2}{*}{2} & Sex & Male & $38(27.1)$ \\
\hline & & Female & $102(72.9)$ \\
\hline \multirow[t]{3}{*}{3} & Marital status & Unmarried & $6(4.3)$ \\
\hline & & Married & $132(94.3)$ \\
\hline & & Widowed & $2(1.4)$ \\
\hline \multirow[t]{2}{*}{4} & No of family members & $\leq 4$ persons & $117(83.6)$ \\
\hline & & $>4$ persons & $23(16.4)$ \\
\hline \multirow[t]{2}{*}{5} & Type of family & Nuclear & $132(94.3)$ \\
\hline & & Joint & $8(5.7)$ \\
\hline \multirow[t]{4}{*}{6} & Socioeconomic Status & Upper class & $24(17.1)$ \\
\hline & & Upper middle class & $74(52.9)$ \\
\hline & & Lower middle class & $24(17.1)$ \\
\hline & & Upper lower class & $18(12.9)$ \\
\hline
\end{tabular}

\section{DISCUSSION}

This study explored the health beliefs of adults in an urban developing health care setting towards screening for hypertension. The study found that the sample of participants could be effectively clustered into six segments with different levels of intention to adopt hypertension screening such as extrinsically motivated with perception of severity and without, intrinsically motivated with risk acceptance and risk denial, unfavourable health belief with negative attitudes focussing mainly on barriers and overall apathy towards screening. The following paragraphs will discuss the importance of these segments, the characteristics of the population in each segment, implications of this segmentation strategy to improve behaviour change communication, strengths and limitations of the study.

\section{Population segments}

According to the Self Determination Theory of learning there are two types of motivations namely intrinsic and extrinsic ${ }^{21,22}$ Intrinsic motivation is the drive to do something because it is perceived as inherently good or beneficial and extrinsic motivation is the drive to do something because it leads to a beneficial effect or is driven by external factors. Both intrinsic and extrinsic motivations for changing behaviour have their respective importance. However there is an understanding that extrinsic motivators are weaker than intrinsic ones. ${ }^{23}$ This study had six distinct segments based on the health belief model two of which were extrinsically motivated predominantly by seeing family and friends suffering from hypertension related complications. One of these extrinsically motivated groups had a high perception of severity whereas the other did not. Their intrinsic motivation levels were low as indicated by low perceived benefits. Two other segments had people who were intrinsically motivated by high perception of benefits and severity of the hypertension levels, thus internally perceiving that hypertension screening is good. However, one of these clusters had a denial of their own risk of susceptibility to hypertension. The fifth cluster was dominated by people who perceived the barriers and did not perceive any benefits of screening and the final cluster had people who were generally apathetic and had no motivation to adopt screening. It is important to try and increase the people in the intrinsically and extrinsically motivated segments and reduce the numbers 


\begin{tabular}{|c|c|c|}
\hline S.No & Statements in each domain & $\begin{array}{l}\text { Factor } \\
\text { weights }\end{array}$ \\
\hline \multicolumn{3}{|c|}{ Perceived Benefits } \\
\hline 1 & Doing BP measurements regularly ensures good health and social security. & .810 \\
\hline 2 & Doing BP measurements regularly will help me prevent complications from hypertension. & .809 \\
\hline 3 & Doing BP measurements regularly is good for my health. & .794 \\
\hline 4 & Doing BP measurements regularly will help me prevent the disease by life style modifications. & .789 \\
\hline 5 & Doing BP measurements regularly will keep me updated about my health status. & .747 \\
\hline 6 & Doing BP measurements regularly will help me detect the disease in a earlier stage. & .720 \\
\hline \multicolumn{3}{|c|}{ Perceived Barriers } \\
\hline 7 & As the clinic is far away from my home, I don’t take up hypertension screening. & .785 \\
\hline 8 & Going to hospital and getting screened is time consuming, I don't take up hypertension screening. & .763 \\
\hline 9 & As I lose a day’s salary by going to the clinic, I don't take up hypertension screening. & .750 \\
\hline 10 & Checking up BP in a clinic costs me some money, which I can use for other purposes & .583 \\
\hline 11 & Taking up screening alone does not prevent me from becoming hypertensive. & .344 \\
\hline \multicolumn{3}{|c|}{ Perceived Susceptibility } \\
\hline 12 & My physical health makes it more likely that I will get hypertension. & .711 \\
\hline 13 & My chances of getting hypertension are great. & .691 \\
\hline 14 & Within the next year I will get hypertension. & .609 \\
\hline 15 & Due to increased stress in my life, my chances of getting hypertension are great. & .596 \\
\hline 16 & I am healthy, I cannot develop hypertension. & -.575 \\
\hline 17 & As my parents are hypertensive my chances of getting hypertension are great. & .450 \\
\hline 18 & I worry a lot about getting hypertension. & .352 \\
\hline 19 & Due to my high salt diet, my chances of getting hypertension are high & .272 \\
\hline \multicolumn{3}{|c|}{ Perceived Severity } \\
\hline 20 & I will have to forgo some of my favourite foods, if I become hypertensive. & .581 \\
\hline 21 & If I am hypertensive, I have chances of getting heart attack or stroke. & .543 \\
\hline 22 & If I suffer stroke, I will become dependent on others for my everyday activities. & .498 \\
\hline 23 & If I get hypertension my family will suffer a lot. & .480 \\
\hline 24 & My feelings about myself will be endangered if I had hypertension. & .451 \\
\hline 25 & Problems I would experience from hypertension would last long. & .393 \\
\hline 26 & My financial security will get endangered if I get hypertension. & .351 \\
\hline 27 & if I become hypertensive, I would end up spending more on medications. & .350 \\
\hline \multicolumn{3}{|c|}{ Cues to Action } \\
\hline 28 & I have seen a friend of mine suffer heart attack because of hypertension. & .853 \\
\hline 29 & I have seen a friend of mine suffer stroke because of hypertension. & .834 \\
\hline 30 & My friend who was as healthy as I am, was recently diagnosed of hypertension. & .723 \\
\hline 31 & My family member is hypertensive. & .653 \\
\hline 32 & Seeing awareness advertisements in newspapers and television induces me to take up screening. & .354 \\
\hline 33 & My work place runs a screening program once a year. & .338 \\
\hline 34 & The local pharmacy has a facility to freely screen my BP. & .312 \\
\hline
\end{tabular}

\begin{tabular}{cccccccc}
\multicolumn{6}{c}{ Table 3: Cluster centres of the six clusters divided based on the five domain factor scores. } \\
Domains & Cluster 1 & Cluster 2 & Cluster 3 & Cluster 4 & Cluster 5 & Cluster 6 \\
\hline Perceived benefits & -.81688 & .98102 & -.97467 & 1.29076 & .41139 & .10553 \\
Perceived barriers & -1.64064 & -.05866 & .88368 & .37752 & -.14966 & -.42405 \\
Cues to action & .72276 & -2.57685 & .04702 & .52679 & .80682 & -.87033 \\
Perceived susceptibility & -.21859 & .30247 & .27885 & -.36591 & .30529 & -.28385 \\
Perceived severity & 1.18909 & 1.78475 & .13064 & 1.10489 & -.86114 & -.36930 \\
\hline
\end{tabular}



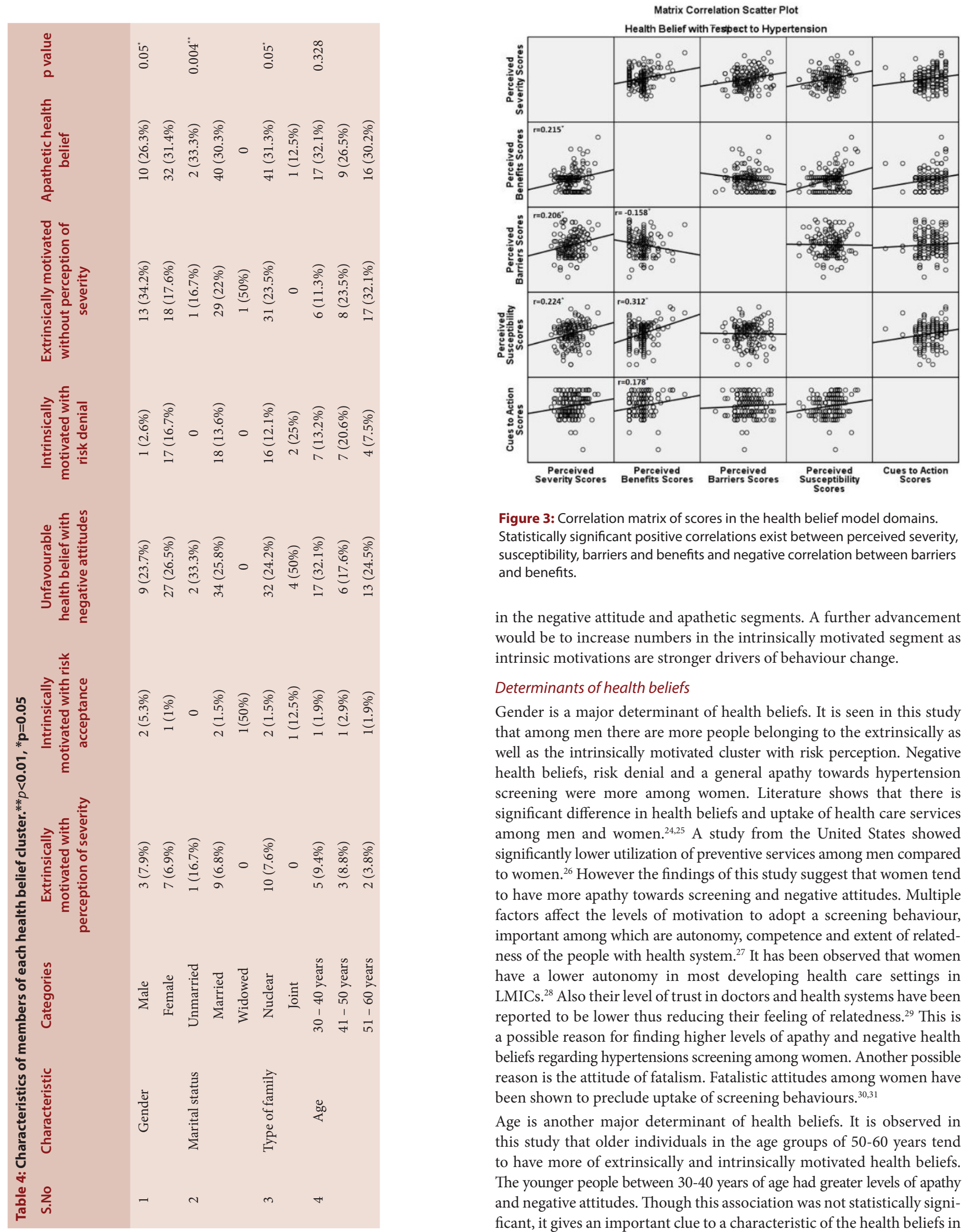

Figure 3: Correlation matrix of scores in the health belief model domains. Statistically significant positive correlations exist between perceived severity, susceptibility, barriers and benefits and negative correlation between barriers and benefits.

in the negative attitude and apathetic segments. A further advancement would be to increase numbers in the intrinsically motivated segment as intrinsic motivations are stronger drivers of behaviour change.

\section{Determinants of health beliefs}

Gender is a major determinant of health beliefs. It is seen in this study that among men there are more people belonging to the extrinsically as well as the intrinsically motivated cluster with risk perception. Negative health beliefs, risk denial and a general apathy towards hypertension screening were more among women. Literature shows that there is significant difference in health beliefs and uptake of health care services among men and women. ${ }^{24,25}$ A study from the United States showed significantly lower utilization of preventive services among men compared to women. ${ }^{26}$ However the findings of this study suggest that women tend to have more apathy towards screening and negative attitudes. Multiple factors affect the levels of motivation to adopt a screening behaviour, important among which are autonomy, competence and extent of relatedness of the people with health system. ${ }^{27}$ It has been observed that women have a lower autonomy in most developing health care settings in LMICs. ${ }^{28}$ Also their level of trust in doctors and health systems have been reported to be lower thus reducing their feeling of relatedness. ${ }^{29}$ This is a possible reason for finding higher levels of apathy and negative health beliefs regarding hypertensions screening among women. Another possible reason is the attitude of fatalism. Fatalistic attitudes among women have been shown to preclude uptake of screening behaviours. ${ }^{30,31}$

Age is another major determinant of health beliefs. It is observed in this study that older individuals in the age groups of 50-60 years tend to have more of extrinsically and intrinsically motivated health beliefs. The younger people between 30-40 years of age had greater levels of apathy and negative attitudes. Though this association was not statistically significant, it gives an important clue to a characteristic of the health beliefs in 
Gopichandran, et al:: Health Beliefs on Hypertension Screening

a community. A study of health beliefs related to HIV treatment showed that younger people had poorer self-efficacy, lack of perceived benefits and poorer attitudes towards treatment. ${ }^{32}$ Another study showed that increasing age led to increased utilization of preventive health care services. ${ }^{33}$ In this study it was seen that marital status also significantly influenced the health beliefs. Unmarried individuals had greater tendency to belong to the negative and apathetic health belief clusters. Being married has been reported to be associated with more proactive and motivated health beliefs compared to being single. ${ }^{34}$ Several theories of the relationship between marital status and good health outcomes have been posited, important among which are that marital status offers good social support and increases positive health behaviours. ${ }^{35,36}$ The type of family in which people live was also found to have a significant relationship with their health belief. Those living in joint families had more negative beliefs dominated by perception of barriers. This was probably because of higher family responsibilities which place their own health beliefs in the backseat. A more detailed exploration of this determinant is required.

\section{Implications of segmentation strategy to improve hypertension screening uptake}

As seen before, the importance of this segmentation is that it has provided specific groups of people whose characteristics are now known and the hypertension awareness generation and screening programs can be adapted differently to each segment to improve behaviour change. For the extrinsically motivated groups more among men, older age groups and married individuals, interventions should focus on highlighting the intrinsic health benefits of undertaking screening programs. For the intrinsically motivate group with risk denial, focussed interventions should aim at emphasizing susceptibility of all individuals to hypertension. It is for the group of younger, unmarried and women who belong to the apathetic and negative health belief clusters that more concerted behaviour change communication should be focussed. They should receive not just awareness programs, but also supportive and enabling environment for taking up hypertension screening. Such targeted interventions to promote intrinsic motivation and hypertension screening will have its dividend in the long run.

This is study is one of the first to explore population segmentation based on health beliefs to understand the hypertension screening practices in a typical LMIC setting. It has used a systematic and probabilistic sampling design in the community. Although a vast majority of the sample were women belonging to the upper middle class and upper class, the findings are generalizable to these segments of the community. A larger study representing both men and women of different classes should be planned to understand the segmentation more clearly. As in many studies using Likert scales, the analysis has treated the scale as a continuous variable and applied statistical methods. This needs to be interpreted with all the necessary limitations of such use in mind.

\section{CONCLUSION}

In conclusion, the health belief model can be effectively used to segment the population into groups that are different by virtue of their motivation types and attitudes towards screening. This segmentation may be effectively used for targeted behaviour change communication.

\section{ACKNOWLEDGEMENT}

The authors would like to acknowledge the help of Ms. Divya A, Mr. Prashanth Kumar, Mr. Rakesh Ruban and Mr. Joel Blesso in data collection.

\section{CONFLICT OF INTEREST}

The authors have no conflicts of interests to declare.

\section{ABBREVIATIONS USED}

LMIC: Low and Middle Income Countries; ESIC: Employees State Insurance Corporation; BP: Blood Pressure; HIV: Human Immunodeficiency Virus.

\section{SUMMARY}

As hypertension is mainly a silent disease, screening behavior is essential for its diagnosis and treatment. This study attempted to identify the health beliefs of adults in a Chennai urban population. The questionnaire-based survey revealed that there were six categories of individuals based on their motivation to undergo regular hypertension screening. Older age, male gender, married status and nuclear family positively influenced health beliefs regarding screening for hypertension. This segmentation based on their health beliefs is useful to target behavior change communication messages to these groups.

\section{REFERENCES}

1. Gupta R. Trends in hypertension epidemiology in India. J Hum Hypertens. 2004;18(2)73-8.

2. Das SK, Sanyal K, Basu A. Study of urban community survey in India: growing trend of high prevalence of hypertension in a developing country. Int J Med Sci. 2005;2(2):70-8.

3. Reddy KS, Shah B, Varghese C, Ramadoss A. Responding to the threat of chronic diseases in India. Lancet Elsevier. 2005;366(9498):1744-9.

4. Mohan S, Reddy KS, Prabhakaran D. Chronic non-communicable diseases in India: reversing the tide. Public Health Foundation of India, New Delhi. 2011 Available on: http://re.indiaenvironmentportal.org.in/files/file/PHFI_NCD_ Report_Sep_2011.pdf Accessed on: 11.11.2017

5. Chobanian AV, Bakris GL, Black HR, Cushman WC, Green LA, Izzo Jr JL, et al. The seventh report of the joint national committee on prevention, detection, evaluation, and treatment of high blood pressure: the JNC 7 report. J Am Med Assoc. 2003;139(2)289:2560-71.

6. Durao S, Ajumobi O, Kredo T, Naude C, Levitt NS, Steyn K, et al. Evidence insufficient to confirm the value of population screening for diabetes and hypertension in low-and middle-income settings. South African Med J. 2015;105(2):98-101.

7. Mohan S, Campbell N, Chockalingam A. Time to effectively address hypertension in India. Indian J Med Res. 2013;137(4)627.

8. Dasgupta K, Quinn RR, Zarnke KB, Rabi DM, Ravani P, Daskalopoulou SS, et al. The 2014 Canadian Hypertension Education Program recommendations for blood pressure measurement, diagnosis, and assessment of risk, prevention, and treatment of hypertension. Can. J Cardiol. 2014;30(5):485-501.

9. Bajpai N, Goyal S. Primary health care in India: Coverage and quality issues Centre for Globalization and Sustainable Development Working Paper 2004. Accessed at: file:///C:/Users/vijay/AppData/Local/Packages/Microsoft MicrosoftEdge_8wekyb3d8bbwe/TempState/Downloads/3._bajpai_primaryhealth_2004_15.pdf Accessed on: 11.11.2017

10. Kusuma YS. Perceptions on hypertension among migrants in Delhi, India: a qualitative study. BMC Public Health. 2009;9(1):267.

11. Marshall IJ, Wolfe CDA, McKevitt C. Lay perspectives on hypertension and drug adherence: systematic review of qualitative research. Br Med J. 2012;345. doi: https://doi.org/10.1136/bmj.e3953

12. Green EC, Murphy E. Health belief model. Wiley Blackwell Encycl. Heal IIIness Behav Soc. 2014. DOI: 10.1002/9781118410868.wbehibs410

13. Darnton A. Practical Guide: An overview of behaviour change models and their uses. Gov. Soc. Res. Unit Available at: www.gsr.gov.uk/downloads/resources/ behaviour_change_review/practical_guide.pdf. 2008 Accessed on: 11.11.2017

14. Smith RA, Greenberg M, Parrott RL. Segmenting by risk perceptions: predicting young adults' genetic-belief profiles with health and opinion-leader covariates. Health Commun. 2014;29(5):483-93

15. Chon MG, Park H. One does not fit all: Health audience segmentation and prediction of health behaviors in cancer prevention. Health Mark Q. 2017;34(3): 202-16.

16. Registrar General I. Census of India 2011: provisional population totals-India data sheet. Off. Regist. Gen. Census Comm. India. Indian Census Bur. 2011 
17. Mohan V, Deepa M, Farooq S, Datta M, Deepa R. Prevalence, awareness and control of hypertension in Chennai-the Chennai urban rural epidemiology study (CURES-52). J. Assoc Physicians India. 2007;55:326-32.

18. Bhatia S, Khanka BS, Singh D, Shankar P, Tutu S, Lakhani P, et al. Study of knowledge, attitude and practice of general population of Lucknow towards hypertension. Int J Curr Micriobio. App Sci. 2015;3(8):680-5.

19. Frankenfield KM. Health belief model of breast cancer screening for female college students. 2009. Available at: http://commons.emich.edu/cgi/viewcontent.cgi?article=1257andcontext=theses Accessed on: 11.11.2017

20. Oberoi SS. Updating the income ranges for Kuppuswamy's socioeconomic status scale for the year 2014. Ind J Pub Health. 2014;59(2):156-7.

21. Deci EL, Ryan RM. Self-determination theory. Hand Theor Soc Psychol. 2011;1:416-33

22. Deci EL, Ryan RM. Self-determination theory: A macrotheory of human motivation, development, and health. Can Psychol. 2008;49(3):182.

23. Ryan RM, Deci EL. Intrinsic and extrinsic motivations: Classic definitions and new directions. Contemp Educ Psychol. 2000;25(1):54-67.

24. Courtenay WH, McCreary DR, Merighi JR. Gender and ethnic differences in health beliefs and behaviors. Health Psychol. 2002;7(3):219-31.

25. Kandrack M-A, Grant KR, Segall A. Gender differences in health related behaviour: some unanswered questions. Soc Sci Med. 1991;32(5):579-90.

26. Vaidya V, Partha G, Karmakar M. Gender differences in utilization of preventive care services in the United States. J Women's Heal. 2012;21(2):140-5.

27. Ryan RM, Patrick H, Deci EL, Williams GC. Facilitating health behaviour change and its maintenance: Interventions based on self-determination theory. Eur
Heal Psychol. 2008;10(1):2-5.

28. Shaikh BT, Hatcher J. Health seeking behaviour and health service utilization in Pakistan: challenging the policy makers. J Public Health. 2005;27(1):49-54

29. Gopichandran V, Chetlapalli SK. Trust in the physician-patient relationship in developing healthcare settings: a quantitative exploration. Indian Med Ethics. 2015;12:141-8.

30. Straughan PT, Seow A. Fatalism reconceptualized: a concept to predict health screening behavior. J Gender Cult. Heal. 1998;3(2):85-100.

31. Straughan PT, Seow A. Attitudes as barriers in breast screening: a prospective study among Singapore women. Soc Sci Med. 2000;51(11):1695-703.

32. Barclay TR, Hinkin CH, Castellon SA, Mason KI, Reinhard MJ, Marion SD, et al. Age-associated predictors of medication adherence in HIV-positive adults: health beliefs, self-efficacy, and neurocognitive status. Heal Psychol. 2007;26(1):40.

33. Yen S-M, Kung P-T, and Tsai W-C. Factors associated with free adult preventive health care utilization among physically disabled people in Taiwan: nationwide population-based study. BMC Health Serv Res. 2014;14(1):610.

34. Markey CN, Markey PM, Schneider C, Brownlee S. Marital status and health beliefs: Different relations for men and women. Sex Roles. 2005;53(1):443-51.

35. Kiecolt-Glaser JK, Newton TL. Marriage and health: his and hers. Psychol Bull. $2001 ; 127(4): 472$.

36. Markey CN, Markey PM, Birch LL. Interpersonal predictors of dieting practices among married couples. J Fam Psychol. 2001;15(3):464.

Cite this article : Neelakandan BV, Gopalakrishnan S, Ramachandran H, Anuradha R, Gopichandran V. Health Beliefs Regarding Uptake of Hypertension Screening in an Urban Setting: A Population Segmentation Strategy. Int J Med Public Health. 2018;8(1):11-17. 